\title{
Autophagy inhibition impairs the epithelial-mesenchymal transition and enhances cisplatin sensitivity in nasopharyngeal carcinoma
}

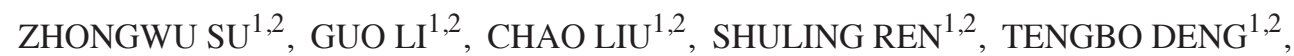 \\ SHUITING ZHANG ${ }^{1,2}$, YONGQUAN TIAN ${ }^{1,2}$, YONG LIU ${ }^{1,2}$ and YUANZHENG QIU ${ }^{1,2}$ \\ ${ }^{1}$ Department of Otolaryngology Head and Neck Surgery, Xiangya Hospital, Central South University; \\ ${ }^{2}$ Otolaryngology Major Disease Research Key Laboratory of Hunan, Changsha, Hunan 410008, P.R. China
}

Received March 5, 2016; Accepted February 17, 2017

DOI: $10.3892 / 01.2017 .5963$

\begin{abstract}
Drug resistance restricts the efficacy of cisplatin in the treatment of nasopharyngeal carcinoma (NPC). Increasing evidence indicates that autophagy and the epithelial-mesenchymal transition (EMT) participate in cancer progression and drug sensitivity. The aim of the present study was to investigate the function of autophagy and EMT in cisplatin treatment, and to reveal the underlying impact of autophagy on the EMT process in NPC. Transmission electron microscopy assays and western blot analyses confirmed that cisplatin activates autophagy in NPC cells. Alterations in cell morphology and biomolecular markers confirmed that cisplatin induces the EMT phenotype in NPC cells. Cell viability assays showed that the combination of the autophagy inhibitor chloroquine (CQ) increased the cytotoxicity of cisplatin in NPC cells and that the EMT inducer transforming growth factor $\beta 1$ promoted the resistance to cisplatin in NPC cells. Moreover, autophagy inhibition by CQ and microtubule-associated protein 1 light chain 3B-knockdown reversed the EMT phenotype in NPC cells. In conclusion, autophagy and the EMT process promote cisplatin resistance in NPC cells, while the inhibition of autophagy impairs the EMT process.
\end{abstract}

Correspondence to: Dr Yong Liu or Dr Yuanzheng Qiu, Department of Otolaryngology Head and Neck Surgery, Xiangya Hospital, Central South University, 87 Xiangya Road, Changsha, Hunan 410008, P.R. China

E-mail: braver19840112@hotmail.com

E-mail: xyqyz@hotmail.com

Abbreviations: NPC, nasopharyngeal carcinoma; EMT, epithelialmesenchymal transition; CQ, chloroquine; TGF $\beta 1$, transforming growth factor $\beta 1$; LC3B, microtubule-associated protein 1 light chain $3 \beta$; TEM, transmission electron microscopy

Key words: autophagy, chemoresistance, chloroquine, cisplatin, epithelial-mesenchymal transition, nasopharyngeal carcinoma

\section{Introduction}

Nasopharyngeal carcinoma (NPC) is a common cancer of the head and neck that is prevalent in Southern China and Southeast Asia (1). Radiotherapy is the primary treatment for this disease, with chemotherapy usually administered in combination with radiotherapy to patients with locally advanced, metastatic or recurrent disease $(1,2)$. Cisplatin-based chemotherapy is the standard first-line regimen for advanced NPC and achieves good responses (1). The major obstacle to the efficacy of cisplatin is drug resistance, the underlying molecular mechanisms of which remain obscure (3). Therefore, dissecting the complicated mechanisms involved in cisplatin resistance in NPC and identifying valuable targets to reverse this resistance, as well as developing novel strategies for improving the clinical efficacy of cisplatin, is of great value.

Autophagy is an evolutionarily conserved degradation and recycling process (4-6). Double-membrane autophagosomes sequester cytoplasmic components, such as damaged proteins and organelles, and fuse with lysosomes to form autolysosomes, in which cytoplasmic components are degraded for recycling (4-6). Microtubule-associated protein 1 light chain $3 \beta$ (LC3B) is a mammalian homologue of the protein autophagy-related gene 8 (Atg8) in yeast. LC3B exists in two forms: LC3B-I and LC3B-II. LC3B-I is a non-lipidated form that can be modified to the lipidated form, LC3B-II, which is closely correlated with the number of autophagosomes (7). Autophagy proceeds at a low basal level in cells to maintain cellular homeostasis, but is activated in response to different forms of metabolic stress, including nutrient starvation, growth factor depletion and hypoxia (4-6). Tumour cells can utilize autophagy to evade death induced by chemotherapies, with the inhibition of autophagy enhancing drug cytotoxicity (8-10). Nevertheless, certain evidence suggests that autophagy is not cytoprotective, but is necessary for the anticancer effect of drugs (11-13). This 'double-edged sword' characteristic of autophagy necessitates the identification of its precise role in chemotherapy under specific tumour settings.

The epithelial-mesenchymal transition (EMT) is a process by which epithelial cells transform into a mesenchymal phenotype with increased mobility (14). It is well known that the 
EMT facilitates a potential mechanism of metastasis, by which epithelial cancer cells detach from adjacent cells and invade the surrounding stroma (15). Moreover, compelling evidence has indicated that the EMT of tumour cells also contributes to the chemoresistance to drugs, including cisplatin $(16,17)$. Previously, autophagy induction was shown to impair migration and invasion by reversing the EMT in glioblastoma cells, indicating the presence of a potential link between autophagy and the EMT (18). However, this link is controversial and the effect of autophagy on the EMT process in NPC has not been investigated. The present study therefore aimed to clarify the role of autophagy and EMT in response to cisplatin treatment in NPC and to identify the underlying impact of autophagy on the EMT process.

\section{Materials and methods}

Reagents. Cisplatin and CQ were purchased from SigmaAldrich (Merck KGaA, Darmstadt, Germany). Recombinant human transforming growth factor $\beta 1$ (TGF $\beta 1$ ) was purchased from Peprotech Inc. (Rocky Hill, NJ, USA). The polyclonal mouse anti-glyceraldehyde 3-phosphate dehydrogenase (GAPDH) antibody (catalogue no. AG019), secondary antibodies HRP-labeled goat anti-rabbit IgG (catalogue no. A0208) and HRP-labelled goat anti-mouse IgG (catalogue no. A0216), cell lysis buffer for Western and IP, BeyoECL Plus, 4',6-diamidino-2-phenylindole (DAPI) and Cell Counting Kit-8 (CCK-8) were purchased from Beyotime Institute of Biotechnology (Shanghai, China). The monoclonal rabbit antibodies against LC3B (catalogue no. 3868), E-cadherin (catalogue no. 3195) and vimentin (catalogue no. 5741) were purchased from Cell Signalling Technology (Danvers, MA, USA). Fluorescein isothiocyanate (FITC)-conjugated secondary antibody goat anti-rabbit IgG (catalogue no. 70-GAR001) was purchased from MultiSciences Biotech Co., Ltd. (Hangzhou, China). LC3B small interfering RNA (siRNA; catalogue no. sc-43390) and control siRNA (catalogue no. sc-37007) were purchased from Santa Cruz (Dallas, TX, USA). The riboFECT ${ }^{\mathrm{Tm}}$ Transfection kit was purchase from Guangzhou RiboBio Co., Ltd. (Guangzhou, China). TRIzol Reagent was purchased from Invitrogen (Thermo Fisher Scientific Inc., Waltham, MA, USA). The SuperQuickRT MasterMix kit and the UltraSYBR Mixture kit were purchased from Beijing ComWin Biotech Co., Ltd. (Beijing, China).

Cell culture. The poorly-differentiated NPC 6-10B and 5-8F cell lines were purchased from the Cell Centre of Central South University (Changsha, China). The cells were cultured in RPMI-1640 medium (Hyclone; GE Healthcare Life Sciences, Logan, UT, USA) supplemented with $10 \%$ foetal bovine serum (FBS), $100 \mathrm{U} / \mathrm{ml}$ penicillin and $100 \mu \mathrm{g} / \mathrm{ml}$ streptomycin (all Gibco; Thermo Fisher Scientific, Inc.) at $37^{\circ} \mathrm{C}$ in a humidified atmosphere with $5 \% \mathrm{CO}_{2}$. All experiments were conducted on cells in the logarithmic growth stage.

Transmission electron microscopy (TEM). The 6-10B cells were incubated with $2 \mu \mathrm{g} / \mathrm{ml}$ cisplatin or vehicle for $24 \mathrm{~h}$, and then collected and centrifuged at $1,000 \times \mathrm{g}$ for $10 \mathrm{~min}$ at $4^{\circ} \mathrm{C}$. The cells incubated with vehicle were used as the control group. The cells were fixed with $2.5 \%$ glutaraldehyde for $24 \mathrm{~h}$ and $2 \%$ osmic acid for $2 \mathrm{~h}$. The fixed samples were dehydrated with increasing concentrations (50-70\%) of acetone. Next, the samples were infiltrated in the mixed liquor of epoxy resin and acetone for $24 \mathrm{~h}$ at $37^{\circ} \mathrm{C}$ and finally embedded in epoxy resin for $24 \mathrm{~h}$ at $60^{\circ} \mathrm{C}$. Ultrathin sections were prepared with an ultramicrotome, and then stained with uranyl acetate and lead citrate. The sections were observed under a transmission electron microscope (Hitachi HT-7700; Hitachi, Ltd., Tokyo, Japan).

Cell viability assay. Cell viability was measured using the CCK-8 assay according to the manufacturer's instructions. In brief, the $6-10 \mathrm{~B}$ and $5-8 \mathrm{~F}$ cells were cultured at $3 \times 10^{3} /$ well in triplicate in 96-well plates and allowed to attach for $12 \mathrm{~h}$. The complete RPMI-1640 medium was then removed and replaced with fresh medium containing drugs. The 6-10B and $5-8 \mathrm{~F}$ cells were treated with cisplatin $(0.31-10 \mu \mathrm{g} / \mathrm{ml})$ and CQ $(10 \mu \mathrm{M})$ or cisplatin and vehicle for $48 \mathrm{~h}$ at $37^{\circ} \mathrm{C}$. For the TGF $\beta 1$ treatment, the $6-10 \mathrm{~B}$ and $5-8 \mathrm{~F}$ cells were pre-incubated with TGF $\beta 1(10 \mathrm{ng} / \mathrm{ml})$ or vehicle for $24 \mathrm{~h}$ at $37^{\circ} \mathrm{C}$, followed by the addition of cisplatin $(0.31-10 \mu \mathrm{g} / \mathrm{ml})$ for $48 \mathrm{~h}$ at $37^{\circ} \mathrm{C}$. Subsequently, the absorbance was determined at a wavelength of $450 \mathrm{~nm}$ using a microplate reader (BioTek Instruments, Inc., Winooski, VT, USA). Cell viability was calculated by dividing the absorbance values of the treated cells by that of the control cells.

Immunofluorescence staining. The 6-10B and 5-8F cells were seeded at a concentration of $1 \times 10^{5}$ cells/well in 12-well plates and allowed to attach for $12 \mathrm{~h}$ at $37^{\circ} \mathrm{C}$. The $6-10 \mathrm{~B}$ and $5-8 \mathrm{~F}$ cells were treated with TGF $\beta 1(10 \mathrm{ng} / \mathrm{ml})$ or vehicle for $48 \mathrm{~h}$ at $37^{\circ} \mathrm{C}$. For the CQ treatment, the $6-10 \mathrm{~B}$ and $5-8 \mathrm{~F}$ cells were pre-incubated with TGF $\beta 1(10 \mathrm{ng} / \mathrm{ml})$ for $24 \mathrm{~h}$ and followed by the addition of CQ $(10 \mu \mathrm{M})$ or vehicle for $48 \mathrm{~h}$ at $37^{\circ} \mathrm{C}$. Subsequently, the cells were fixed with $4 \%$ paraformaldehyde for $10 \mathrm{~min}$, permeabilized with $0.5 \%$ Triton X-100 for $15 \mathrm{~min}$ and then blocked with $1 \%$ bovine serum albumin (BSA) for $30 \mathrm{~min}$. The cells were incubated with primary antibody (vimentin, 1:200) diluted with $1 \% \mathrm{BSA}$ at $37^{\circ} \mathrm{C}$ for $1 \mathrm{~h}$, followed by FITC-conjugated secondary antibody $(1: 200)$ at $37^{\circ} \mathrm{C}$ for $1 \mathrm{~h}$. The cells were then counterstained with DAPI and examined using a fluorescence microscope (Leica Microscopes $\mathrm{GmbH}$, Wetzlar, Germany).

Western blotting. The 6-10B and 5-8F cells were washed three times with PBS and then lysed with cell lysis buffer for $30 \mathrm{~min}$ on ice. The lysates were centrifuged at $12,000 \mathrm{x} g$ for $10 \mathrm{~min}$ at $4^{\circ} \mathrm{C}$. The supernatants were collected for western blot analyses. Total protein $(50 \mu \mathrm{g})$ was separated by $12 \%$ SDS-PAGE and transferred onto polyvinylidene difluoride membranes (EMD Millipore, Billerica, MA, USA). After blocked with $5 \%$ non-fat milk for $1 \mathrm{~h}$ at room temperature, the blotted membranes were incubated with the corresponding primary antibodies overnight at $4^{\circ} \mathrm{C}$, followed by the relevant secondary antibodies for $1 \mathrm{~h}$ at room temperature. The primary antibodies included monoclonal rabbit anti-LC3B (1:800), E-cadherin (1:800), vimentin (1:800) and polyclonal mouse anti-GAPDH $(1: 1,000)$. The blots were detected using BeyoECL Plus reagent and exposed in a ChemiDoc MP imaging system (Bio-Rad Laboratories, Inc.). 

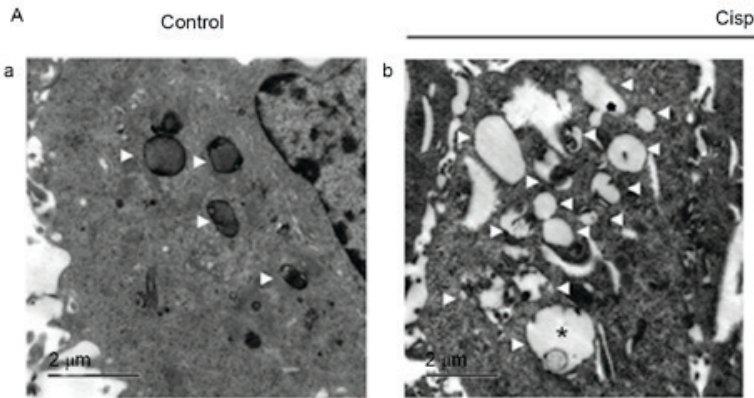

Cisplatin

B

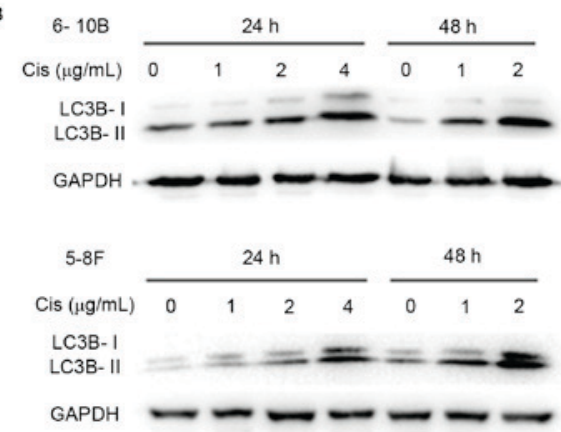

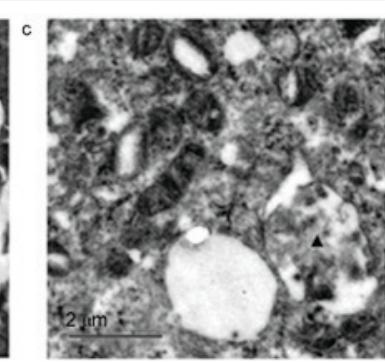

C
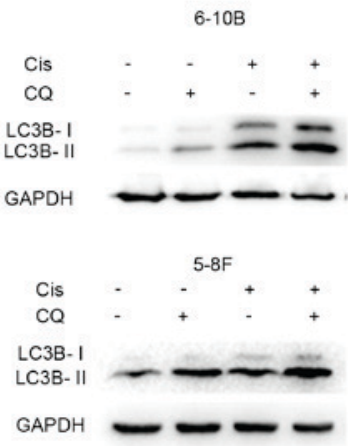
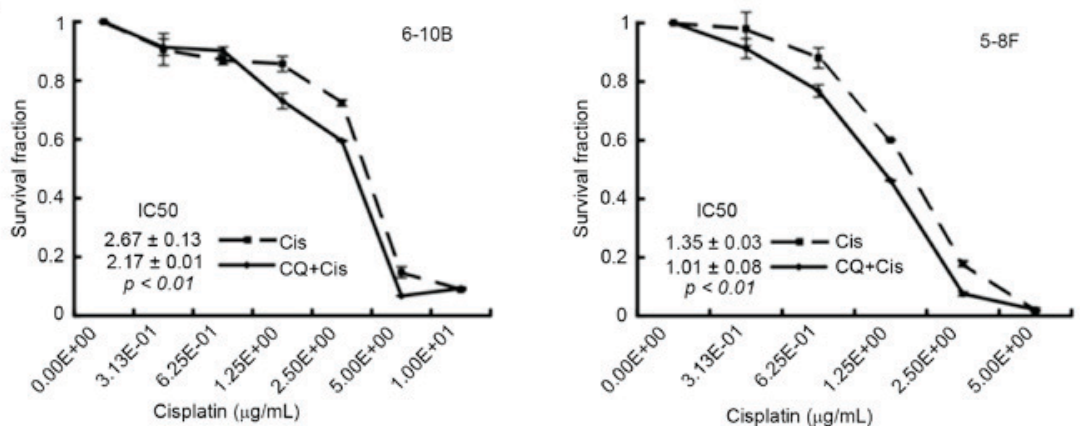

Figure 1. Cisplatin induces autophagy, while the inhibition of autophagy by CQ elevates the cytotoxicity of cisplatin in 6-10B and 5-8F nasopharyngeal carcinoma cells. (A) The 6-10B cells were incubated with (Aa) vehicle or with (Ab and Ac) $2 \mu \mathrm{g} / \mathrm{ml}$ cisplatin for $24 \mathrm{~h}$ and then subjected to transmission electron microscopy. White triangles denote an autophagic vacuole, the asterisk denotes an early autophagic vacuole and the black triangle denotes a degradative autophagic vacuole. (B) The 6-10bB and 5-8F cells were treated with $0,1,2$ or $4 \mu \mathrm{g} / \mathrm{ml}$ cisplatin for 24 or $48 \mathrm{~h}$. Western blot analysis revealed a dose- and time-dependent increase in LC3B-II expression in the cisplatin-treated 6-10B and 5-8F cells. (C) The 6-10B and 5-8F cells were incubated with $2 \mu \mathrm{g} / \mathrm{ml}$ cisplatin and/or $10 \mu \mathrm{M}$ CQ for $24 \mathrm{~h}$. Western blot analysis showed that cisplatin enhanced the expression of LC3B-II, and the combination of cisplatin and CQ resulted in more LC3B-II expression. (D) The 6-10B and 5-8F cells were treated with increasing concentrations of cisplatin ( $0.31-10 \mu \mathrm{g} / \mathrm{ml})$ in the presence or absence of $10 \mu \mathrm{M}$ CQ for $48 \mathrm{~h}$. The CCK-8 assay revealed that the $\mathrm{IC}_{50}$ value decreased in the CQ group compared with the blank group $(6-10 \mathrm{~B}$ cells: $2.17 \pm 0.01$ vs. $2.67 \pm 0.13, \mathrm{P}<0.01 ; 5-8 \mathrm{~F}$ cells: $1.01 \pm 0.08$ vs. $1.35 \pm 0.03, \mathrm{P}<0.01)$. Cis, cisplatin; $\mathrm{CQ}$, chloroquine; LC $3 \mathrm{~B}$, microtubule-associated protein 1 light chain $3 \mathrm{~B}$; $\mathrm{GAPDH}$, glyceraldehyde 3-phosphate dehydrogenase; $\mathrm{IC}_{50}$, half-maximal inhibitory concentration.

siRNA transfection. The 6-10B cells were transfected with LC3B siRNA or control siRNA using the riboFECT ${ }^{\mathrm{TM}}$ Transfection kit according to the manufacturer's protocol. The transfected cells were collected after a 72-h incubation and the efficacy of the siRNA knockdown was determined by western blot assay.

Reverse transcription-quantitative polymerase chain reaction $(R T-q P C R)$. Total RNA from the $6-10 \mathrm{~B}$ cells was isolated using TRIzol reagent according to the manufacturer's protocol. Total RNA (1 $\mu \mathrm{g})$ was reverse-transcribed using a SuperQuickRT MasterMix kit. qPCR was performed using an UltraSYBR Mixture kit in a Bio-Rad IQ5 ${ }^{\mathrm{TM}}$ Multicolor Real-Time PCR detection system (Bio-Rad Laboratories, Inc., Hercules, CA, USA). The cycling conditions used were as follows: $95^{\circ} \mathrm{C}$ for $10 \mathrm{~min}, 95^{\circ} \mathrm{C}$ for $15 \mathrm{sec}$ and $62.5^{\circ} \mathrm{C}$ for $60 \mathrm{sec}$ for 45 cycles. qPCR quantification was conducted using the $2^{-\Delta \Delta \mathrm{Ct}}$ method (19). The following primer sequences were used: E-cadherin forward, 5'-TGCCCAGAAAATGAA AAAGG-3' and reverse, 5'-GTGTATGTGGCAATGCGT TC-3'; Vimentin forward, 5'-GAGAACTTTGCCGTTGAA GC-3' and reverse, 5'-TCCAGCAGCTTCCTGTAGGT-3'; Snail forward, 5'-GCGAGCTGCAGGACTCTAAT-3' and reverse, 5'-GGACAGAGTCCCAGATGAGC-3'; Slug forward, 5'-TTCGGACCCACACATTACCT-3' and reverse, 5'-TGA CCTGTCTGCAAATGCTC-3'; and $\beta$-actin forward, 5'-CTC TTCCAGCCTTCCTTCCT-3' and reverse, 5'-AGCACTGTG TTGGCGTACAG-3'.

Statistical analysis. All experiments were performed at least three times. Statistical analysis was performed using SPSS 13.0 software (SPSS, Inc., Chicago, IL, USA). Quantitative data were expressed as the mean \pm standard deviation. Comparison between two groups was performed using a two-sided, 

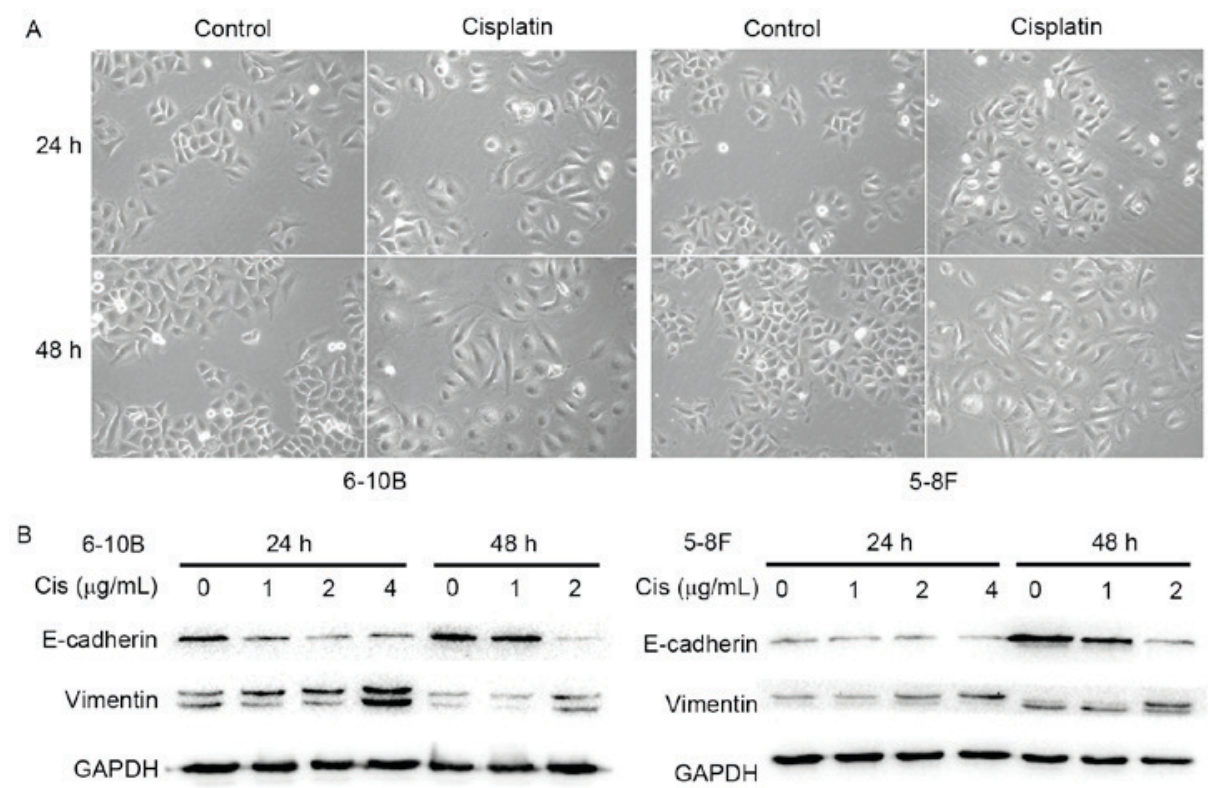

Figure 2. Cisplatin-induced epithelial-mesenchymal transition phenotype in nasopharyngeal carcinoma 6-10B and 5-8F cells. (A) The 6-10B and 5-8F cells were treated with $2 \mu \mathrm{g} / \mathrm{ml}$ cisplatin for 24 or $48 \mathrm{~h}$. Cell morphology was visualized using a phase-contrast microscope. Cisplatin-treated 6-10B and 5-8F cells gradually exhibited a spindle-like morphology, with more pseudopodia and fewer cell-cell contacts (x200 magnification). (B) The 6-10B and 5-8F cells were treated with $0,1,2$, or $4 \mu \mathrm{g} / \mathrm{ml}$ cisplatin for 24 or $48 \mathrm{~h}$, and then western blot analysis showed that cisplatin treatment induced an increase in vimentin and a decrease in E-cadherin. Cis, cisplatin; GAPDH, glyceraldehyde 3-phosphate dehydrogenase.

unpaired Student's t-test. $\mathrm{P}<0.05$ was considered to indicate a statistically significant difference.

\section{Results}

Cisplatin induces autophagy, the inhibition of which enhances the cytotoxicity of cisplatin in NPC cells. To clarify the effects of cisplatin on autophagy in NPC cells, TEM assays were initially performed to visualize autophagic vacuoles, which are canonical morphological alterations of autophagy and indicate the occurrence of autophagy (7). After a 24-h incubation with cisplatin, the 6-10B cells contained more autophagic vacuoles than the control cells, including early autophagic vacuoles and late degradative autophagic vacuoles (Fig. 1A). Next, the expression of LC3B-II in the cells under cisplatin treatment was assessed by western blot analysis. Cisplatin incubation increased the level of LC3B-II in a dose- and time-dependent manner in the $5-8 \mathrm{~F}$ and $6-10 \mathrm{~B}$ cells (Fig. 1B). Blocking the late stage of autophagy by the addition of CQ further increased the expression of LC3B-II in cisplatin-treated NPC cells (Fig. 1C), suggesting that cisplatin induces autophagosome accumulation. Finally, the CCK-8 assay revealed that the half-maximal inhibitory concentration $\left(\mathrm{IC}_{50}\right)$ value decreased in the CQ group compared with the control group (6-10B cells: $2.17 \pm 0.01$ vs. $2.67 \pm 0.13, \mathrm{P}<0.01$; 5-8F cells: $1.01 \pm 0.08$ vs. $1.35 \pm 0.03, \mathrm{P}<0.01$ ) (Fig. $1 \mathrm{D}$ ). Collectively, these data suggested that cisplatin induces autophagy and that inhibiting autophagy augments the sensitivity of NPC cells to cisplatin.

Cisplatin induces the EMT phenotype in NPC cells. To clarify the impact of cisplatin on the EMT process, the morphological changes of NPC cells under cisplatin treatment were first observed using an inverted phase-contrast microscope. After
24 or $48 \mathrm{~h}$ of treatment with $2 \mu \mathrm{g} / \mathrm{ml}$ cisplatin, the $6-10 \mathrm{~B}$ and $5-8 \mathrm{~F}$ cells gradually exhibited a spindle-like morphology with pseudopodia and reduced cell-cell contacts (Fig. 2A). These observations suggested that the NPC cells underwent a characteristic EMT morphological change under stimulation with cisplatin. To further elucidate this observation, the expression of EMT-related biomolecules was measured by western blot analysis. A marked decrease in the epithelial marker E-cadherin was observed together with an increase in the mesenchymal marker vimentin in the $6-10 \mathrm{~B}$ and $5-8 \mathrm{~F}$ cells following incubation with cisplatin (Fig. 2B). These results indicated that cisplatin elicits the EMT phenotype in NPC cells.

TGF $\beta 1$ induces EMT and promotes cisplatin resistance in NPC cells. To clarify the role of EMT in cisplatin sensitivity, the NPC cells were firstly treated with TGF $\beta 1$, which is a critical inducer of EMT (15), to activate the EMT process. After a 48-h incubation, immunofluorescence microscopy showed that TGF $\beta 1$-treated NPC cells underwent an EMT-like alteration, characterized by the upregulation of the mesenchymal marker vimentin (Fig. 3A). Results of the CCK-8 assay demonstrated that the $\mathrm{IC}_{50}$ value increased in the TGF $\beta 1$ group compared with the blank group (6-10B: $3.01 \pm 0.01$ vs. $2.42 \pm 0.07, \mathrm{P}<0.01$; 5-8F: $1.30 \pm 0.07$ vs. $1.11 \pm 0.05, \mathrm{P}<0.01$ ) (Fig. $3 \mathrm{~B}$ ). These results indicated that TGF 1 -induced EMT is associated with cisplatin resistance in NPC cells.

Autophagy inhibition impairs the EMT process in NPC cells. To elucidate the effect of autophagy on the EMT process, western blot analysis and immunofluorescence microscopy were performed. As shown in Fig. 4A, CQ downregulated the expression of vimentin and upregulated the expression of E-cadherin in the 5-8F and 6-10B cells. 


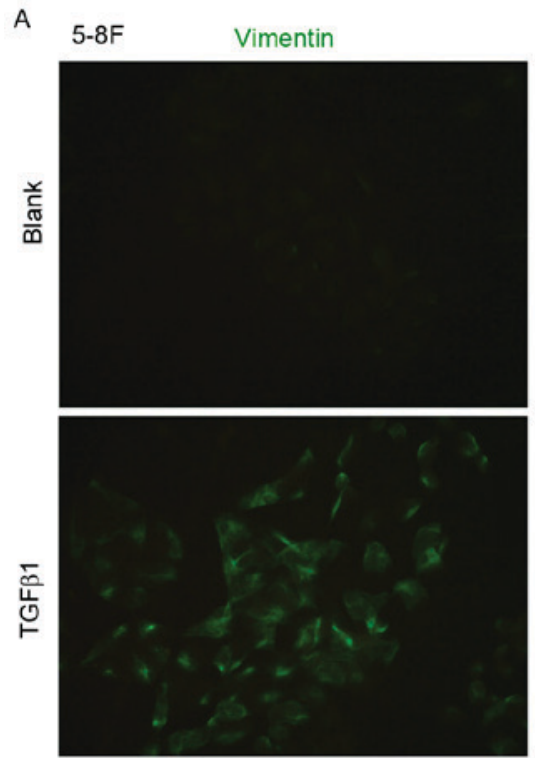

$$
6-10 B
$$
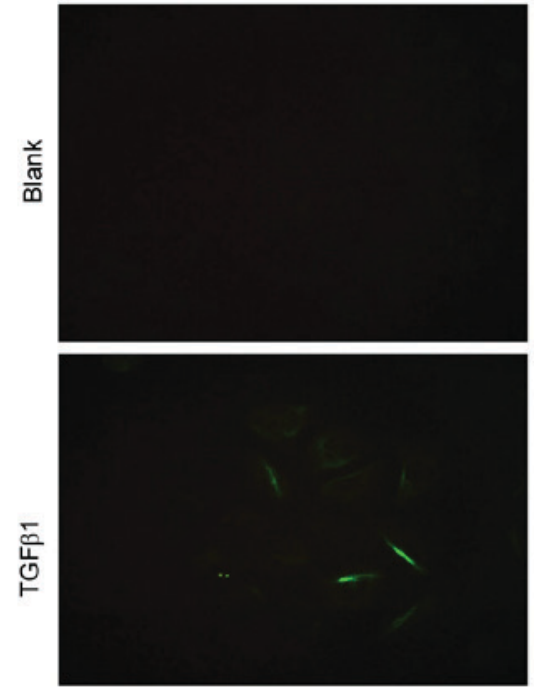

B

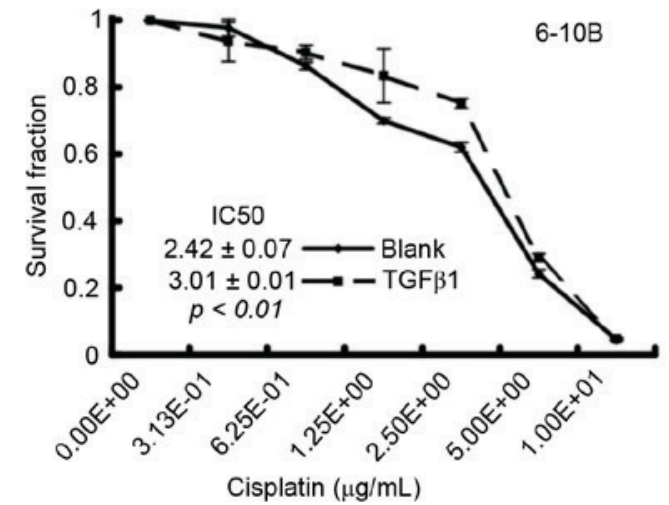

DAPI
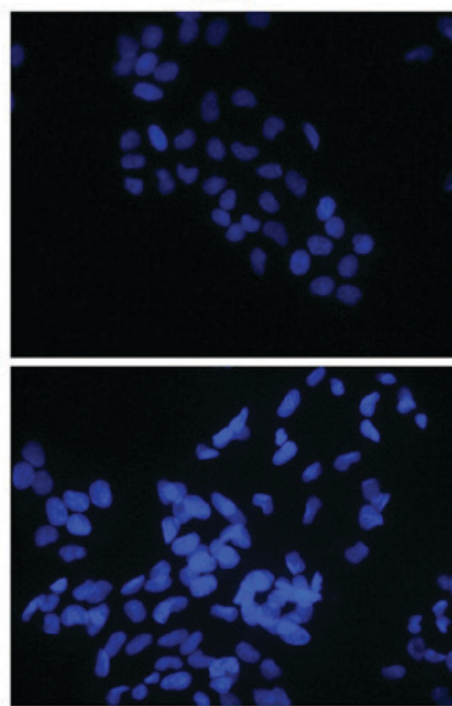

DAPI
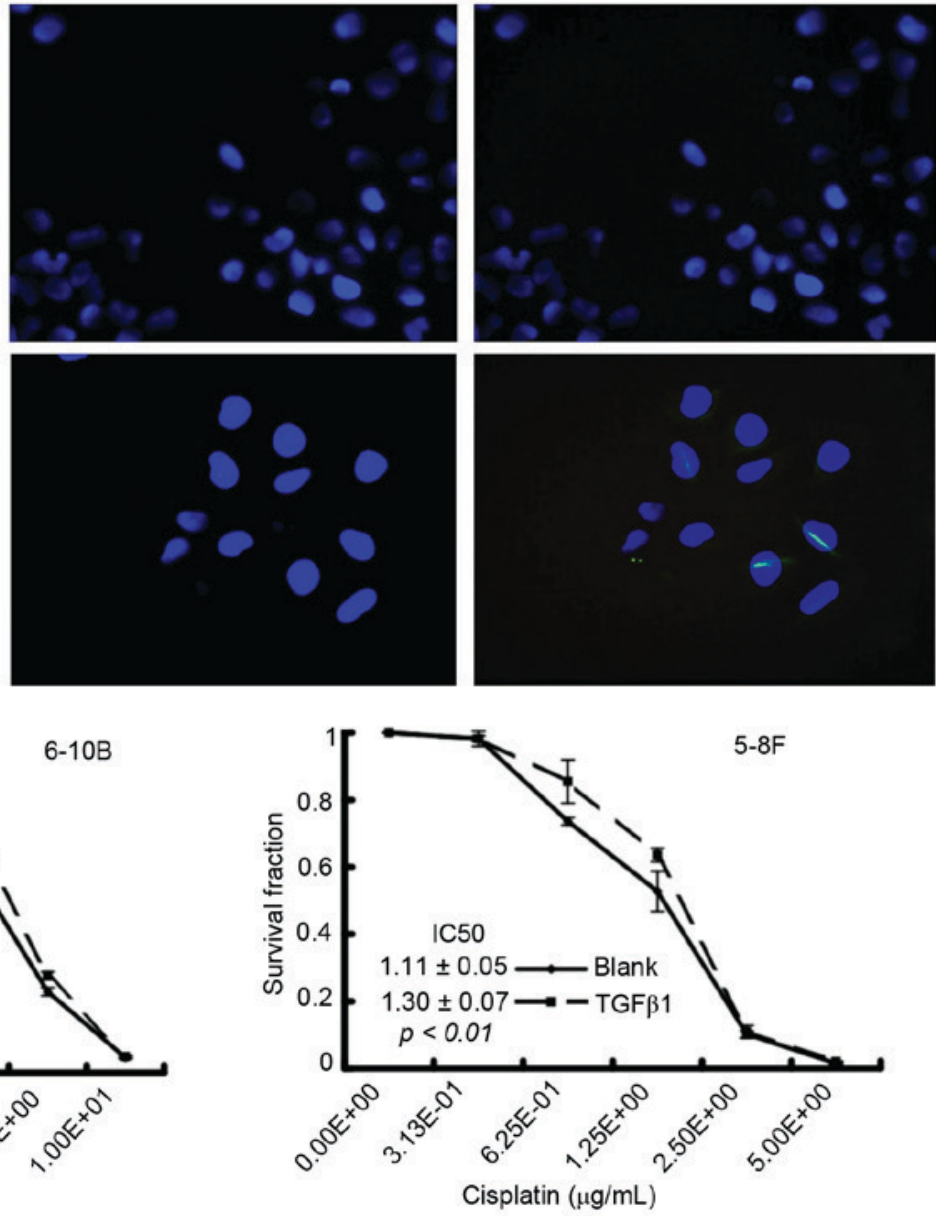

Figure 3. TGF $\beta 1$ induces an epithelial-mesenchymal transition phenotype and increases the resistance to cisplatin in NPC 6-10B and 5-8F cells. (A) The 6-10B and 5-8F cells were exposed to $10 \mathrm{ng} / \mathrm{ml}$ TGF $\beta 1$ for $48 \mathrm{~h}$. Immunofluorescence microscopy showed that TGF $\beta 1$-treated NPC cells exhibited more vimentin fluorescence (green) than the control cells (x400 magnification). (B) The 6-10B and 5-8F cells were pre-incubated with $10 \mathrm{ng} / \mathrm{ml} \mathrm{TGF} \beta 1$ for $24 \mathrm{~h}$ and then exposed to gradient concentration of cisplatin $(0.31-10 \mu \mathrm{g} / \mathrm{ml})$ for $48 \mathrm{~h}$. The $\mathrm{IC}_{50}$ value increased in the TGF $\beta 1$ group compared with the blank group $(6-10 \mathrm{~B}$ : $3.01 \pm 0.01$ vs. $2.42 \pm 0.07, \mathrm{P}<0.01 ; 5-8 \mathrm{~F}: 1.30 \pm 0.07$ vs. $1.11 \pm 0.05, \mathrm{P}<0.01)$. TGF $\beta 1$, transforming growth factor $\beta 1$; NPC, nasopharyngeal carcinoma; IC ${ }_{50}$, half-maximal inhibitory concentration; DAPI, 4',6-diamidino-2-phenylindole.

Moreover, immunofluorescence microscopy showed that CQ inhibited the TGF $\beta 1$-induced increase in vimentin expression, suggesting that CQ reverses the mesenchymal phenotype activated by TGF $\beta 1$ in $5-8 \mathrm{~F}$ and $6-10 \mathrm{~B}$ cells (Fig. 4B). To clarify the association between autophagy and EMT further, basal levels of LC3B protein were detected 
A
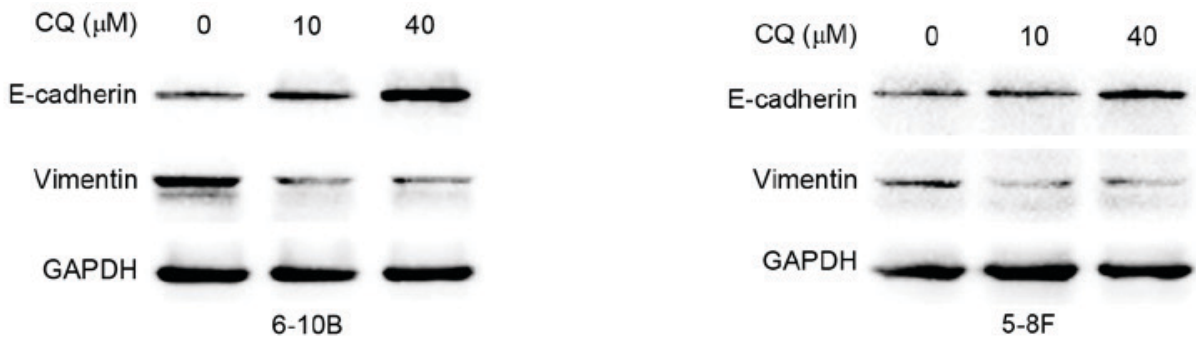

B

$5-8 \mathrm{~F}$

Vimentin

DAPI
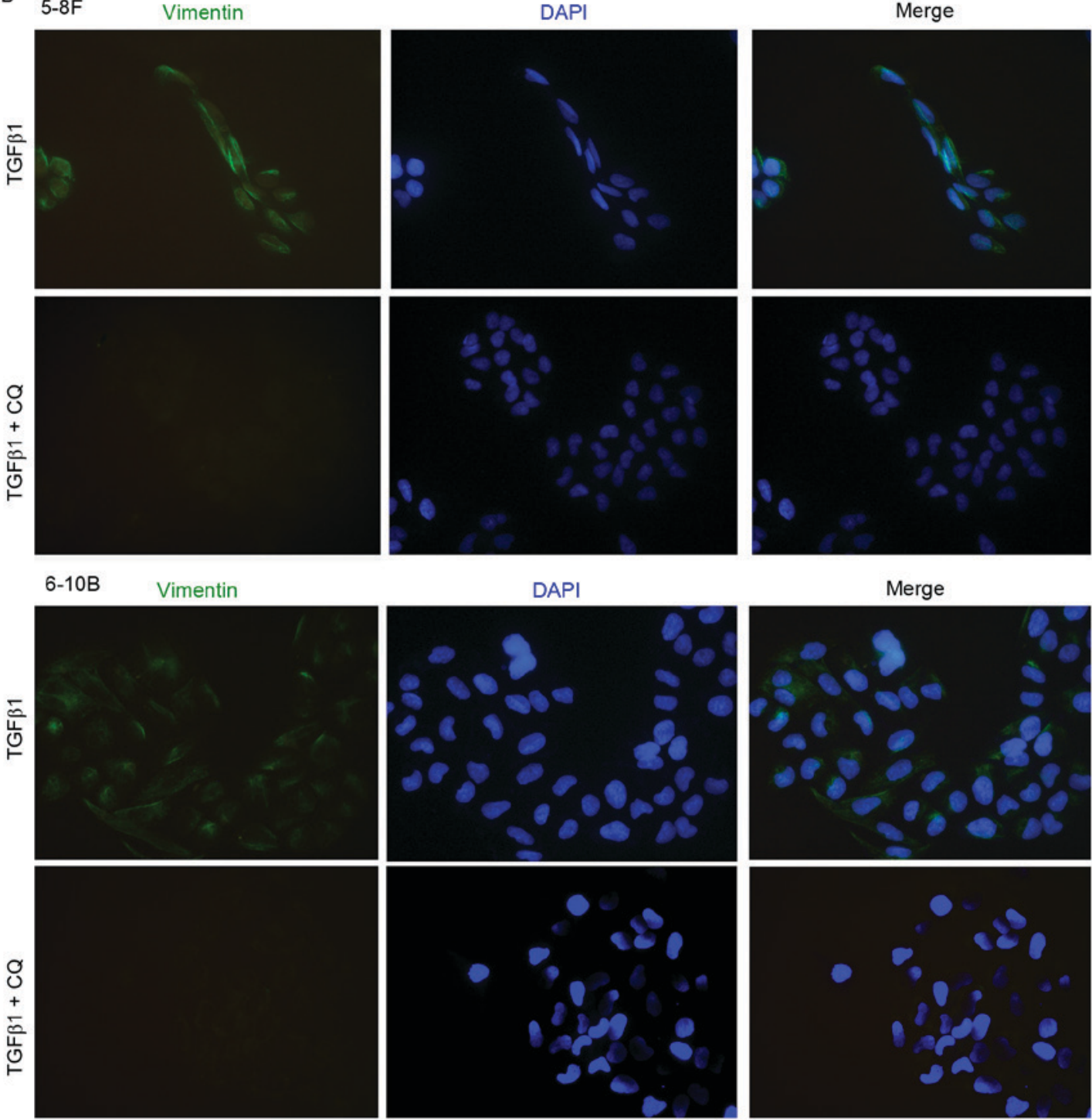

Figure 4. Inhibition of autophagy by CQ impairs the epithelial-mesenchymal transition process in nasopharyngeal carcinoma 6-10B and 5-8F cells. (A) The 6-10B and 5-8F cells were exposed to 10 or $40 \mu \mathrm{M} \mathrm{CQ}$ for $48 \mathrm{~h}$. Western blot analysis showed that CQ upregulated the expression of E-cadherin and downregulated the expression of vimentin. (B) The 6-10B and 5-8F cells were pre-incubated with $10 \mathrm{ng} / \mathrm{ml}$ TGF 1 for $24 \mathrm{~h}$ and then exposed to $10 \mu \mathrm{M} \mathrm{CQ}$ for $48 \mathrm{~h}$. Immunofluorescence microscopy revealed that cells treated with TGF $\beta 1$ and CQ displayed fewer vimentin fluorescent signals (green) than cells incubated with TGF31 alone (x400 magnification). CQ, chloroquine; GAPDH, glyceraldehyde 3-phosphate dehydrogenase; DAPI, 4',6-diamidino-2-phenylindole.

in the two NPC cell lines and 6-10B cells demonstrated a higher level of autophagy with a higher expression level of LC3B-II (Fig. 5A). The 6-10B cells were then selected for LC3B-knockdown by siRNA (Fig. 5B and C). LC3B-knockdown increased the amount of E-cadherin mRNA, whereas the amount of vimentin, Snail and Slug mRNA was decreased compared with the control (Fig. 5C). Together, these data indicated that blockage of autophagy impairs the EMT process.

\section{Discussion}

Cisplatin is used in the clinical management of various solid tumours, including NPC (1). Although good responses have been observed, chemoresistance and cytotoxicity limit the use of cisplatin in clinical management. Several mechanisms have been described as being involved in the development of cisplatin resistance, including alterations in drug transport, the DNA repair apparatus and apoptotic signalling 
A

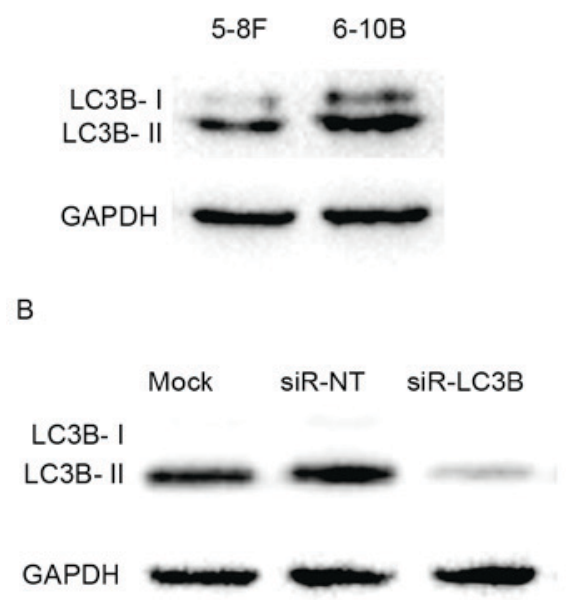

C

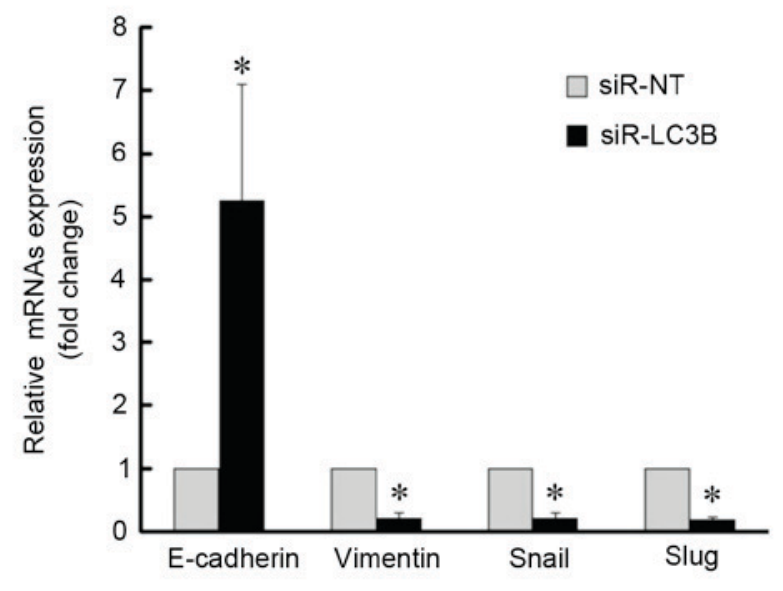

Figure 5. LC3B-knockdown impairs the epithelial-mesenchymal transition process in nasopharyngeal carcinoma 6-10B cells. (A) Western blot analysis showed that the basal level of LC3B was higher in 6-10B cells than in 5-8F cells. (B) Western blot analysis indicated that the expression of LC3B was effectively inhibited by siRNA in 6-10B cells. (C) Reverse transcription-quantitative PCR revealed that LC3B-knockdown upregulated E-cadherin mRNA expression and downregulated vimentin, Snail and Slug mRNA expression levels. mRNA levels were normalized to $\beta$-actin ( $\mathrm{P}<0.05$ vs. siR-NT group). siR-NT, control small interfering RNA nucleotides; LC3B, microtubule-associated protein 1 light chain 3B; GAPDH, glyceraldehyde 3-phosphate dehydrogenase.

pathways $(3,20)$. Nevertheless, the molecular mechanism of cisplatin resistance remains poorly understood. Previously, autophagy and EMT, two interrelated biological processes, have been proposed to participate in chemoresistance. In the present study, it was found that cisplatin elicited cytoprotective autophagy and EMT in NPC cells. Inhibition of autophagy enhanced sensitivity to cisplatin, whereas activating the EMT process promoted resistance to cisplatin in NPC cells. Moreover, inhibition of autophagy impaired the EMT process in NPC cells.

EMT always characterizes advanced neoplastic lesions. As such, EMT has been proposed to promote cancer metastasis, the cancer stem-cell phenotype, immune evasion, and radiotherapy and drug resistance $(14,21,22)$. Tumour cells able to survive chemotherapy treatment exhibit an EMT phenotype. In NPC, paclitaxel- and cisplatin-resistant NPC cells transform into a mesenchymal phenotype $(23,24)$. In the present study, NPC cells underwent characteristic morphological and molecular transformations, such as EMT, upon cisplatin treatment. Furthermore, TGF $\beta 1$, a well-known inducer of EMT, induced the EMT phenotype and promoted cisplatin resistance in the NPC cells, supporting the theory that the EMT process establishes a resistance phenotype to cisplatin treatment in NPC.

Autophagy affects drug sensitivity in tumour treatment, and can serve as either a mechanism of drug resistance or a mechanism of killing tumour cells (25). Chloroquine is a well-established inhibitor of autophagy that blocks the late stage of autophagy by preventing lysosomal degradation (7). The present study demonstrates that treatment with cisplatin induced autophagy in the NPC cells. Autophagy inhibition by CQ enhanced sensitivity to cisplatin in NPC cells. This result was consistent with that of another study, in which combining the autophagy inhibitor 3-methyladenine with cisplatin resulted in enhanced cell death in NPC cells in vitro (26). Use of CQ is much safer in patients than 3-methyladenine and has been adopted to inhibit autophagy in clinical trials for cancer treatment (25).
Autophagy and the EMT process share a number of common features. The two processes can, for example, be activated by adverse stresses, including starvation and hypoxia $(27,28)$. The well-documented EMT inducer TGF- $\beta$ can activate autophagy $(29,30)$, whereas the inhibition of mammalian target of rapamycin, an important mediator of autophagy, can trigger the EMT process $(31,32)$. The connection between autophagy and EMT has gradually emerged in the past few years. In breast cancer, autophagy activation is involved in the degradation of the Snail and Twist transcription factors, which are significant inducers of the EMT process (33). Induction of autophagy has been shown to impair migration and invasion in glioblastoma, triggering a molecular switch from a mesenchymal phenotype to an epithelial-like one (18). These lines of evidence have confirmed that autophagy can inhibit the EMT process in tumours. Conversely, however, Li et al reported that autophagy induces EMT and enhances the invasion capability of hepatocellular carcinoma (34). Blockade of autophagy by either gene knockdown or CQ treatment promoted the reversal of the mesenchymal phenotype and decreased the cancer stem cell phenotype in breast cancer (35). In the present study, under treatment with cisplatin, the surviving NPC cells established a defensive phenotype, with autophagy and EMT activated. Blockage of autophagy by CQ reversed the mesenchymal phenotype in the NPC cells, a novel finding of this study. Moreover, knockdown of LC3B increased the expression of E-cadherin mRNA, whereas expression of vimentin, Snail and Slug mRNA was decreased in the NPC cells. Snail and Slug are transcription factors that repress the expression of E-cadherin and induce EMT (15). Autophagy may therefore regulate the expression of EMT-related transcription factors, switching the EMT phenotype in NPC.

In summary, the present study indicated that cisplatin activates autophagy and EMT in NPC cells and that the two processes contribute to the resistance to cisplatin. Moreover, inhibition of autophagy promotes the reversal of the EMT process. Blockage of autophagy, therefore, represents an 
encouraging strategy to reverse drug-induced adaptive responses (i.e., autophagy and EMT) and to overcome chemoresistance in NPC management.

\section{Acknowledgements}

Grants were provided by the National Natural Science Foundation of China (nos. 81372426, 81172558 and No. 81202128) and the Natural Science Foundation of Hunan Province (nos. 14JJ2018 and 2015JJ3137).

\section{References}

1. Chan AT: Nasopharyngeal carcinoma. Ann Oncol 21 (Suppl 7): i308-i312, 2010.

2. Chua DT, Sham JS and Au GK: A phase II study of docetaxel and cisplatin as first-line chemotherapy in patients with metastatic nasopharyngeal carcinoma. Oral Oncol 41: 589-595, 2005.

3. Galluzzi L, Vitale I, Michels J, Brenner C, Szabadkai G, Harel-Bellan A, Castedo M and Kroemer G: Systems biology of cisplatin resistance: Past, present and future. Cell Death Dis 5: e1257, 2014.

4. Galluzzi L, Pietrocola F, Bravo-San Pedro JM, Amaravadi RK, Baehrecke EH, Cecconi F, Codogno P, Debnath J, Gewirtz DA, Karantza V, et al: Autophagy in malignant transformation and cancer progression. Embo J 7: 856-880, 2015.

5. Levine B and Kroemer G: Autophagy in the pathogenesis of disease. Cell 132: 27-42, 2008

6. Sun K, Deng W, Zhang S, Cai N, Jiao S, Song J and Wei L: Paradoxical roles of autophagy in different stages of tumorigenesis: Protector for normal or cancer cells. Cell Biosci 3: 35, 2013

7. Klionsky DJ, Abdalla FC, Abeliovich H, Abraham RT, Acevedo-Arozena A, Adeli K, Agholme L, Agnello M, Agostinis P, Aguirre-Ghiso JA, et al: Guidelines for the use and interpretation of assays for monitoring autophagy. Autophagy 8 : 445-544, 2012.

8. He J, Yu JJ, Xu Q, Wang L, Zheng JZ, Liu LZ and Jiang BH: Downregulation of ATG14 by EGR1-MIR152 sensitizes ovarian cancer cells to cisplatin-induced apoptosis by inhibiting cyto-protective autophagy. Autophagy 11: 373-384, 2015.

9. Hashimoto D, Bläuer M, Hirota M, Ikonen NH, Sand J and Laukkarinen J: Autophagy is needed for the growth of pancreatic adenocarcinoma and has a cytoprotective effect against anticancer drugs. Eur J Cancer 50: 1382-1390, 2014

10. Cufi S, Vazquez-Martin A, Oliveras-Ferraros C, CorominasFaja $\mathrm{B}$, Cuyàs $\mathrm{E}$, López-Bonet $\mathrm{E}$, Martin-Castillo $\mathrm{B}$, Joven J and Menendez JA: The anti-malarial chloroquine overcomes primary resistance and restores sensitivity to trastuzumab in HER2-positive breast cancer. Sci Rep 3: 2469, 2013.

11. Fulda S and Kögel D: Cell death by autophagy: Emerging molecular mechanisms and implications for cancer therapy. Oncogene 34: 5105-5113, 2015.

12. Liu YL, Yang PM, Shun CT, Wu MS, Weng JR and Chen CC: Autophagy potentiates the anti-cancer effects of the histone deacetylase inhibitors in hepatocellular carcinoma. Autophag y 6 : 1057-1065, 2010

13. Salazar M, Carracedo A, Salanueva IJ, Hernández-Tiedra S, Lorente M, Egia A, Vázquez P, Blázquez C, Torres S, García S, et al: Cannabinoid action induces autophagy-mediated cell death through stimulation of ER stress in human glioma cells. J Clin Invest 119: 1359-1372, 2009.

14. Dave B, Mittal V, Tan NM and Chang JC: Epithelial-mesenchymal transition, cancer stem cells and treatment resistance. Breast Cancer Res 14: 202, 2012.

15. Micalizzi DS and Ford HL: Epithelial-mesenchymal transition in development and cancer. Future Oncol 5: 1129-1143, 2009.

16. Singh A and Settleman J: EMT, cancer stem cells and drug resistance: An emerging axis of evil in the war on cancer. Oncogene 29: 4741-4751, 2010.
17. Zhu X, Shen H, Yin X, Long L, Xie C, Liu Y, Hui L, Lin X, Fang Y, Cao Y, et al: miR-186 regulation of Twistl and ovarian cancer sensitivity to cisplatin. Oncogene 35: 323-332, 2016.

18. Catalano M,D'Alessandro G,Lepore F, Corazzari M, Caldarola S, Valacca C, Faienza F, Esposito V, Limatola C, Cecconi F and Di Bartolomeo S: Autophagy induction impairs migration and invasion by reversing EMT in glioblastoma cells. Mol Oncol 9: $1612-1625,2015$

19. Livak KJ and Schmittgen TD: Analysis of relative gene expression data using real-time quantitative PCR and the 2(-Delta Delta C(T)) Method. Methods 25: 402-408, 2001.

20. Galluzzi L, Senovilla L, Vitale I, Michels J, Martins I, Kepp O, Castedo M and Kroemer G: Molecular mechanisms of cisplatin resistance. Oncogene 31: 1869-1883, 2012

21. Nantajit D, Lin D and Li JJ: The network of epithelial-mesenchymal transition: Potential new targets for tumor resistance. J Cancer Res Clin Oncol 141: 1697-1713, 2014.

22. Akalay I, Janji B, Hasmim M, Noman MZ, André F, De Cremoux P, Bertheau P, Badoual C, Vielh P, Larsen AK, et al: Epithelial-to-mesenchymal transition and autophagy induction in breast carcinoma promote escape from T-cell-mediated lysis. Cancer Res 73: 2418-2427, 2013.

23. Zhou Z, Zhang L, Xie B, Wang X, Yang X, Ding N, Zhang J, Liu Q, Tan G, Feng D and Sun LQ: FOXC2 promotes chemoresistance in nasopharyngeal carcinomas via induction of epithelial mesenchymal transition. Cancer Lett 363: 137-145, 2015.

24. Zhang P, Liu H, Xia F, Zhang QW, Zhang YY, Zhao Q, Chao ZH, Jiang ZW and Jiang CC: Epithelial-mesenchymal transition is necessary for acquired resistance to cisplatin and increases the metastatic potential of nasopharyngeal carcinoma cells. Int J Mol Med 33: 151-159, 2014.

25. Thorburn A, Thamm DH and Gustafson DL: Autophagy and cancer therapy. Mol Pharmacol 85: 830-838, 2014.

26. Song L, Liu H, Ma L, Zhang X, Jiang Z and Jiang C: Inhibition of autophagy by 3-MA enhances endoplasmic reticulum stress-induced apoptosis in human nasopharyngeal carcinoma cells. Oncol Lett 6: 1031-1038, 2013.

27. Talbot LJ, Bhattacharya SD and Kuo PC: Epithelial-mesenchymal transition, the tumor microenvironment and metastatic behavior of epithelial malignancies. Int J Biochem Mol Biol 3: 117-136, 2012.

28. Klymkowsky MW and Savagner P: Epithelial-mesenchymal transition: A cancer researcher's conceptual friend and foe. Am J Pathol 174: 1588-1593, 2009.

29. Kiyono K, Suzuki HI, Matsuyama H, Morishita Y, Komuro A, Kano MR, Sugimoto K and Miyazono K: Autophagy is activated by TGF-beta and potentiates TGF-beta-mediated growth inhibition in human hepatocellular carcinoma cells. Cancer Res 69: 8844-8852, 2009.

30. Suzuki HI, Kiyono K and Miyazono K: Regulation of autophagy by transforming growth factor- $\beta$ (TGF- $\beta$ ) signaling. Autophagy 6 : 645-647, 2010

31. Mikaelian I, Malek M, Gadet R, Viallet J, Garcia A, Girard-Gagnepain A, Hesling C, Gillet G, Gonzalo P, Rimokh R and Billaud M: Genetic and pharmacologic inhibition of mTORC1 promotes EMT by a TGF- $\beta$-independent mechanism. Cancer Res 73: 6621-6631, 2013.

32. Chang L, Graham PH, Hao J, Ni J, Bucci J, Cozzi PJ, Kearsley JH and Li Y: Acquisition of epithelial-mesenchymal transition and cancer stem cell phenotypes is associated with activation of the $\mathrm{PI} 3 \mathrm{~K} / \mathrm{Akt} / \mathrm{mTOR}$ pathway in prostate cancer radioresistance. Cell Death Dis 4: e875, 2013.

33. Lv Q, Wang W, Xue J, Hua F, Mu R, Lin H, Yan J, Lv X, Chen X and $\mathrm{Hu}$ ZW: DEDD interacts with PI3KC3 to activate autophagy and attenuate epithelial-mesenchymal transition in human breast cancer. Cancer Res 72: 3238-3250, 2012.

34. Li J, Yang B, Zhou Q, Wu Y, Shang D, Guo Y, Song Z, Zheng Q and Xiong J: Autophagy promotes hepatocellular carcinoma cell invasion through activation of epithelial-mesenchymal transition. Carcinogenesis 34: 1343-1351, 2013.

35. Cufi S, Vazquez-Martin A, Oliveras-Ferraros C, MartinCastillo B, Vellon L and Menendez JA: Autophagy positively regulates the CD44(+) CD24(-/low) breast cancer stem-like phenotype. Cell Cycle 10: 3871-3885, 2011. 